\title{
SOLUBLE ANTIGENS OF ENTEROPATHOGENIC ESCHERICHIA COLI
}

\author{
K. A. Bettelheim* and Joan Taylor \\ Salmonella Reference Laboratory, Colindale, London
}

IN studies in which the ability of certain strains of Escherichia coli to cause enteritis in man was investigated by feeding living cultures to babies and to adults, it was shown that both the babies (Neter and Shumway, 1950) and adults (Ferguson and June, 1952) developed diarrhoea provided that the number of ingested organisms was large. Another method of investigation was the use of the ligated rabbit gut loop first described by De, Bhattacharya and Sarkar (1956) and Taylor, Maltby and Payne (1958). From this and subsequent work it was shown that certain serotypes isolated from babies with diarrhoea caused dilatation of the rabbit gut loop, but that factors other than the classical $\mathrm{O}$, $\mathrm{K}$ or $\mathrm{H}$ antigens were involved. Taylor and Bettelheim (1966) were able to show that chloroform-killed suspensions of $E$. coli strains that caused diarrhoea in babies gave positive results in the ligated intestinal loop test, whereas similar preparations of antigenically similar strains derived from healthy babies did not. Smith and Halls (1967a and $b, 1968)$ studied the activities of enteropathogenic strains of $E$. coli in ligated intestinal loops of the same host animal as that from which the strain was isolated and also in loops of different animal species; these workers concluded that a number of enterotoxic factors were involved.

In a study of the pathogenicity of $E$. coli (Bettelheim, 1969) it was considered that some of the factors involved in enteropathogenicity might be antigenic. The present paper gives details of a series of investigations in which soluble antigens of test strains were sought in exudates obtained in experiments with ligated loops, extracts of cultures of these strains and extracts of 400 strains that were mainly of human origin. The test antisera were prepared against various strains of $E$. coli treated in various ways.

\section{MATERIALS AND METHODS}

Preparation of antisera. Two types of antisera were prepared, one according to the method described by Ewing (1956) for the preparation of $\mathrm{K}$ antisera in which intravenous inoculations of formalin-killed cultures were followed by the inoculation of living cultures. This type of antiserum was known as "live" or $\mathrm{L}$ and was known to contain $\mathrm{O}$ and $\mathrm{K}$ antibodies. The second type of antiserum was prepared by giving a similar course of inoculations, but with organisms killed with absolute alcohol. Cultures were grown on Hartley digest agar, harvested in about $1 \mathrm{ml}$ sterile saline to which was added $100 \mathrm{ml}$ of absolute alcohol (Analar). The mixture was shaken, then allowed to stand overnight. After centrifugation, a sample of

Received 30 Jan. 1970; accepted 22 Apr. 1970.

* Present address: Dept of Biochemistry, Imperial College, London, S.W.7.

J. MED. MICROBIOL.-VOL. 3 (1970) 655 
the deposit was tested for sterility and at the same time the rest of the deposit was suspended in 0.05 per cent. commercial 40 per cent. formaldehyde (formalin) in buffered physiological

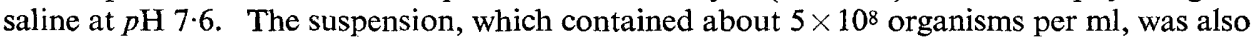
tested for sterility. This method was used because it preserves the $\mathrm{O}$ and $\mathrm{K}$ antigens. This serum was known as " dead " or D. Details of the sera that we prepared are given in table $I$.

Preparation of antigens. Two different types of material were used as antigens, one obtained from rabbit gut and the other from cultures of E. coli. (i) Exudate from ligated rabbit gut loop was obtained when dilatation occurred in response to a test inoculum; when the gut loop contained no exudate the inner surface was scraped and washed with two to three drops of sterile normal saline. (ii) The second type of antigen was prepared from bacterial cultures. Previous work by Taylor, Wilkins and Payne (1961) suggested that cultures grown in a milk medium produced the maximum effect in the ligated loop test. As

TABLE I

Antisera prepared for the study of soluble antigens of Escherichia coli

\begin{tabular}{|c|c|c|c|c|}
\hline $\begin{array}{l}\text { Antiserum } \\
\text { code name }\end{array}$ & $\begin{array}{l}\text { Inoculum } \\
\text { strain }\end{array}$ & $\begin{array}{c}\text { Inoculum } \\
\text { live (L) or dead (D) }\end{array}$ & Serotype & $\begin{array}{l}\text { Intestinal } \\
\text { loop reaction } \\
\text { of strain* }\end{array}$ \\
\hline $\begin{array}{l}\text { E65L } \\
\text { E65D } \\
\mathrm{Ab} \beta L \\
\mathrm{Ab} \beta \mathrm{D} \\
\mathrm{D} 2101 \mathrm{~L} \\
\mathrm{D} 2101 \mathrm{D} \\
\text { E122L } \\
\mathrm{D} 5301 \mathrm{~L} \\
\mathrm{D} 5301 \mathrm{D} \\
\text { E21L }\end{array}$ & $\begin{array}{l}\text { E65 } \\
\text { E65 } \\
\text { Aberdeen } \beta \\
\text { Aberdeen } \beta \\
\text { D2101 } \\
\text { D2101 } \\
\text { E122 } \\
\text { D5301 } \\
\text { D5301 } \\
\text { E21 }\end{array}$ & $\begin{array}{l}\text { L } \\
\text { D } \\
\text { L } \\
\text { D } \\
\text { L } \\
\text { D } \\
\text { L } \\
\text { L } \\
\text { D } \\
\text { L }\end{array}$ & $\begin{array}{c}\text { O26:K60:H- } \\
\text { O26:K60:H- } \\
\text { O55:K } 59: \mathrm{H} 6 \\
\text { O55:K59:H6 } \\
\text { O111:K58:H12 } \\
\text { O111:K } 58: \mathrm{H} 12 \\
\text { O111:K58:H2 } \\
\text { O128:K67:H2 } \\
\text { O128:K67:H2 } \\
\text { O128:K67:H2 }\end{array}$ & $\begin{array}{l}+ \\
+ \\
+ \\
+ \\
- \\
+ \\
+ \\
+\end{array}$ \\
\hline
\end{tabular}

it is not possible to use an opaque medium in gel diffusion studies, we decided to use a medium roughly corresponding in chemical composition to that of milk; this consisted of $20 \mathrm{~g}$ casein hydrolysate and $30 \mathrm{~g}$ dried whey dissolved in distilled water to a final volume of $100 \mathrm{ml}$. The solution was held at $100^{\circ} \mathrm{C}$ in a steamer for $1 \mathrm{hr}$, filtered and adjusted to $p \mathrm{H}$ 7.0 and then sterilised by Seitz filtration. For use, the medium was diluted aseptically, one volume of medium being mixed with 9 volumes of sterile distilled water; $100-\mathrm{ml}$ amounts were put into $100-\mathrm{ml}$ sterile bottles and $5-\mathrm{ml}$ volumes were dispensed in sterile bijou bottles. These containers were closed with tightly fitting metal screw-caps fitted with rubber washers.

The stock cultures used in this part of the study were those used previously in our experimental work on ligated rabbit gut (Taylor and Bettelheim). These strains were stored on Dorset's egg medium. Subcultures were made into the bijou bottles containing $5 \mathrm{ml}$ of medium which were then incubated at $37^{\circ} \mathrm{C}$ for $7-8 \mathrm{hr}$. The contents of each bottle were thereafter transferred to a bottle containing $100 \mathrm{ml}$ of medium and this was incubated at $37^{\circ} \mathrm{C}$ for $16 \mathrm{hr}$. The metal caps of the bottles were screwed down as tightly as possible in order to reduce air exchange.

The cultures were centrifuged at 13,000 r.p.m. in order to precipitate the bacterial growth as compactly as possible. The supernatant fluids were discarded. Each of the bacterial deposits was resuspended by shaking with a mechanical shaker at $37^{\circ} \mathrm{C}$ for $1 \mathrm{hr}$ in $0.5 \mathrm{ml}$ of a buffered azide solution that consisted of $0.02 \mathrm{M}$ sodium phosphate buffer at $p \mathrm{H} 6.0$ containing 0.01 per cent. (w/v) sodium azide. The suspensions were then centrifuged at c. 1000 r.p.m. for $1 \mathrm{hr}$ and the clear supernatant fluid, the extracted antigen, was kept in a sterile screw-capped bottle at $4^{\circ} \mathrm{C}$ until required. Antigens were always tested within 5 days of 
making, but some were re-tested after storage at $4^{\circ} \mathrm{C}$ for 18 months and were found to give identical results.

Immuno-electrophoresis procedures. As power pack for the electrophoresis experiments, an ex-Admiralty Rectifier Unit Des. 95, Ser. No. 158, Patt. 58754 was obtained. A Shandon electrophoresis tank was used. A voltmeter and a milliammeter were also included in the circuit.

Except where otherwise stated, the buffer solution was prepared by mixing $0 \cdot 02 \mathrm{M}$ aqueous solutions of sodium dihydrogen orthophosphate and disodium hydrogen orthophosphate to obtain $p \mathbf{H ~} 6.0$ as determined by glass electrode; sodium azide was added to give 0.01 per cent. w/v. The electrophoresis runs were carried out at room temperature.

The experiments were performed on glass microscope slides to which was applied $5 \mathrm{ml}$ of agar prepared as follows: Ionagar No. 2 (Oxoid) was added to azide buffer solution to a final concentration of 1.2 per cent. agar. This mixture was heated to boiling point in $100-\mathrm{ml}$ amounts and was stirred continuously with a magnetic stirrer. The mixture was then cooled to about $60^{\circ} \mathrm{C}$ and a small quantity was spread on a slide and allowed to dry; then about $5 \mathrm{ml}$ was run on the surface of the dried film. This method ensured that the agar did not float off the slide. A 1-mm-wide trough and a hole of $1-\mathrm{mm}$ diameter placed $2.1 \mathrm{~mm}$ from the trough were made with a Gel Punch set (L.K.B.).

Each test antigen preparation was placed in the hole or " antigen well " of a prepared slide which was immediately transferred to the electrophoresis tank. Electrical contact between the slide and buffer compartments was established with Whatman no. 1 filter-paper soaked in the azide buffer solution.

With the type of power pack used, neither the voltage nor the amperage could be controlled, but when eight slides were placed in the electrophoresis tank in parallel and current was permitted to flow for the standard period of $2 \mathrm{hr}$, the voltage always varied to the same extent from 320 to $310 \mathrm{~V}$ while the milliamperage also varied from 15 to 23 .

At the end of the 2-hr period allowed for electrophoresis, the slides were removed and antiserum was placed in the serum trough. All slides were incubated at room temperature in a humid chamber for $1 \mathrm{wk}$ to permit the formation of precipitin lines. They were examined daily during that period. They were then washed for $1 \mathrm{wk}$ with three changes of azide buffer, and dried by blowing warm air over them; they were then stained with amido black B.

The stained slides were differentiated in the same solvent mixture that was used to dissolve the amido black B, viz., distilled water, ethanol and glacial acetic acid mixed in the ratios $5: 4: 1(\mathrm{v} / \mathrm{v} / \mathrm{v})$.

After overnight drying in the atmosphere at room temperature the processed slides could be handled very easily and were stored in slide boxes where they kept very well.

Preliminary tests were carried out on gut loop exudates in order to determine the $p \mathrm{H}$ at which there was maximum separation of precipitin lines after immuno-electrophoresis. The

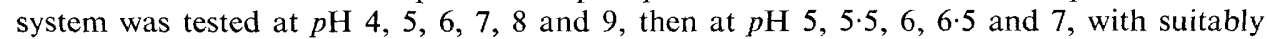
adjusted mixtures of $0.02 \mathrm{M}$ aqueous solutions of sodium orthophosphates. It was found that there was maximum differentiation at $p \mathrm{H} 6$.

\section{RESULTS \\ Studies with material from ligated gut loops}

All gut loop material was cultured before testing; material from uninoculated loops was sterile, whereas inoculated loops contained the test organism in pure culture. The material from the rabbit gut loop contained exudate, rabbit cells, culture medium and the injected $E$. coli, which had multiplied.

When whey casein medium and scrapings from uninoculated gut loops were placed in antigen holes and tested against all sera, no precipitin lines were observed. When an exudate from a test loop was tested against an L or D antiserum specific for the injected organism, a strong precipitin line always 
appeared on the cathode side of the antigen well. When the same exudate was tested against antisera prepared from organisms that were unrelated according to their known $\mathrm{O}, \mathrm{K}$ and $\mathrm{H}$ antigens (Kauffmann, 1969), no precipitin line appeared on the cathode side. This result was consistently obtained, irrespective of whether the antiserum was prepared from living or dead inocula or whether or not the strain had caused dilatation of the gut loop. For this reason we regarded this precipitin line as the somatic or $\mathrm{O}$ line, though it probably represents surface $(\mathrm{K})$ antigens as well, in other words the whole of the somatic complex. There was never any suggestion of a line related to the $\mathrm{H}$ antigen in our preparations.

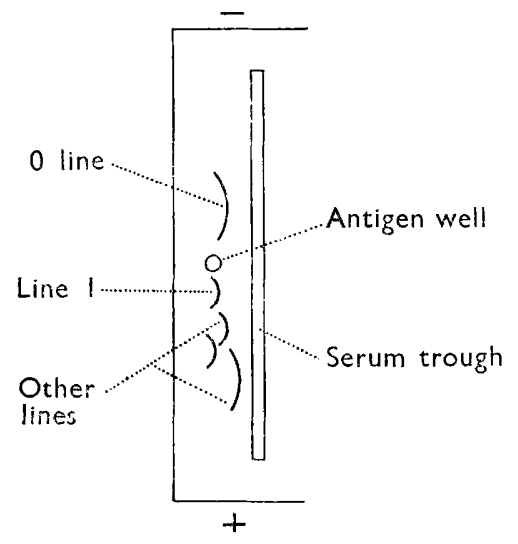

FIG. 1.-Immuno-electrophoresis system used with rabbit gut exudates, showing precipitin lines that developed.

On the anode side of the antigen well a number of lines appeared, some of which were at a distance of about $1 \mathrm{~cm}$ (fig. 1). There was no relation between these lines and the known antigenic structure of the organism in the exudate and the known serum antibodies. For example, an exudate containing strain E65 with the structure $\mathrm{O} 26: \mathrm{K} 60: \mathrm{H}$ - was tested against an $\mathrm{L}$ serum prepared from strain E122 with the structure O111:K58:H2; two lines were formed on the anode side in spite of the fact that the antigenic structure of the $E$. coli strain and the antiserum were not known to be related.

Of these numerous lines on the anode side, one of particular interest was formed when material from the dilated gut loop was tested against any $\mathrm{L}$ serum prepared from a strain of $E$. coli that caused dilatation of the gut loop. This line will be referred to as the line 1 . Line 1 was never formed by any exudate when tested against D sera nor was it formed by washings from gut loops inoculated with $E$. coli strains that were not gut-dilating. The results are shown in table II.

\section{Studies with extracts of cultures}

In the first instance the cultures tested were those used in our previous work to which references have been made.

As in the experiments with exudates, on the cathode side of the antigen 


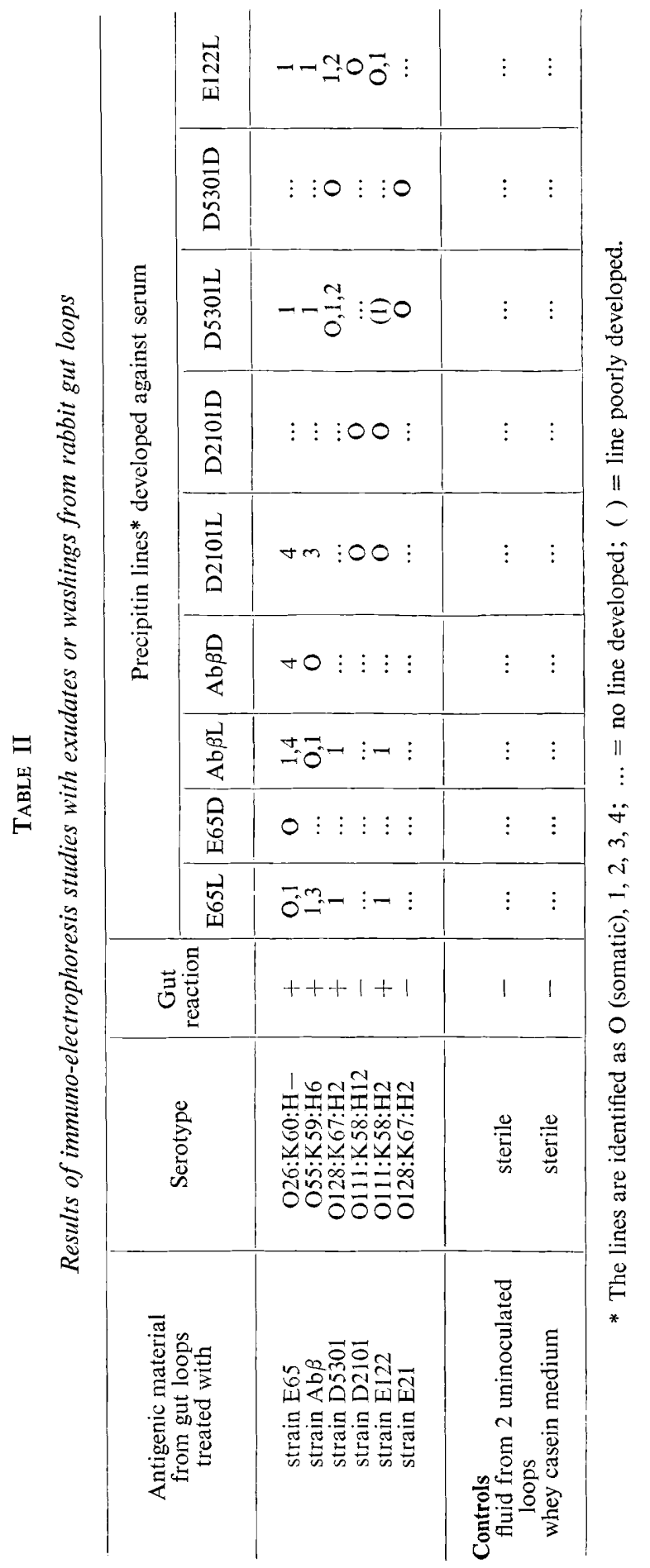


an $O$ precipitin line appeared when the $E$. coli extract was tested against the specific $\mathrm{L}$ or $\mathrm{D}$ serum containing $\mathrm{O}$ antibodies.

On the anode side of the extract well a maximum number of four lines appeared; line 1 has been described above, and lines 2, 3 and 4 were recognised. Line 4 was formed by the majority of antigens when tested against the majority of $\mathrm{L}$ or $\mathrm{D}$ sera; it was very thin with a wide sweep close to the antiserum trough. Line 2 was thin and was rarely found; when it appeared, line 1 was also present. Line 3 was short and appeared closer to the anode. In only one test were all four lines formed from one antigen. Their approximate positions are shown in fig. 2 .

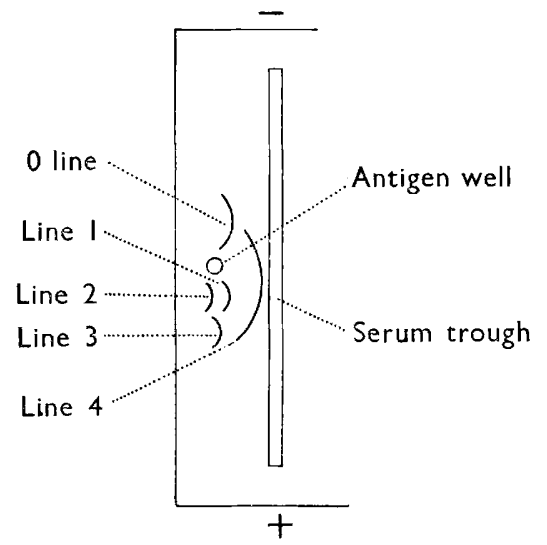

FIG. 2.-Immuno-electrophoresis system used with culture extracts, showing precipitin lines that developed.

Extracts were made from eight cultures; four were labelled positive strains as they had been isolated from babies with infantile enteritis and had produced dilatation of the rabbit gut loop. Four strains were labelled negative as they had been isolated from healthy babies and failed to cause dilatation of the gut loop. The eight extracts were tested against ten antisera and the results are summarised in table III. These results show that line 4 was formed with L or D sera and it bore no relation to the known antigens in the extract nor to the enteropathogenicity of the strain from which the antigen was extracted. Line 3 was formed only when $L$ sera were tested, but again this line bore no relation to the known antigens nor to the enteropathogenicity of the strain extracted.

The results suggest that line 1 was related to enteropathogenicity as it was formed by all positive strains when tested against $\mathrm{L}$ sera prepared from the positive strains E65 and E122. In tests with $L$ or D sera, line 1 was never formed by a strain that failed to cause dilatation of the gut loop. Line 1 was formed only by gut-positive strains when tested against $\mathrm{L}$ antisera prepared against certain gut-positive strains.

Survey of strains of $E$. coli from various sources

Procedure. The antigenic structure of all strains was identified and the extracts of strains prepared as described in the Methods section. The investigation 


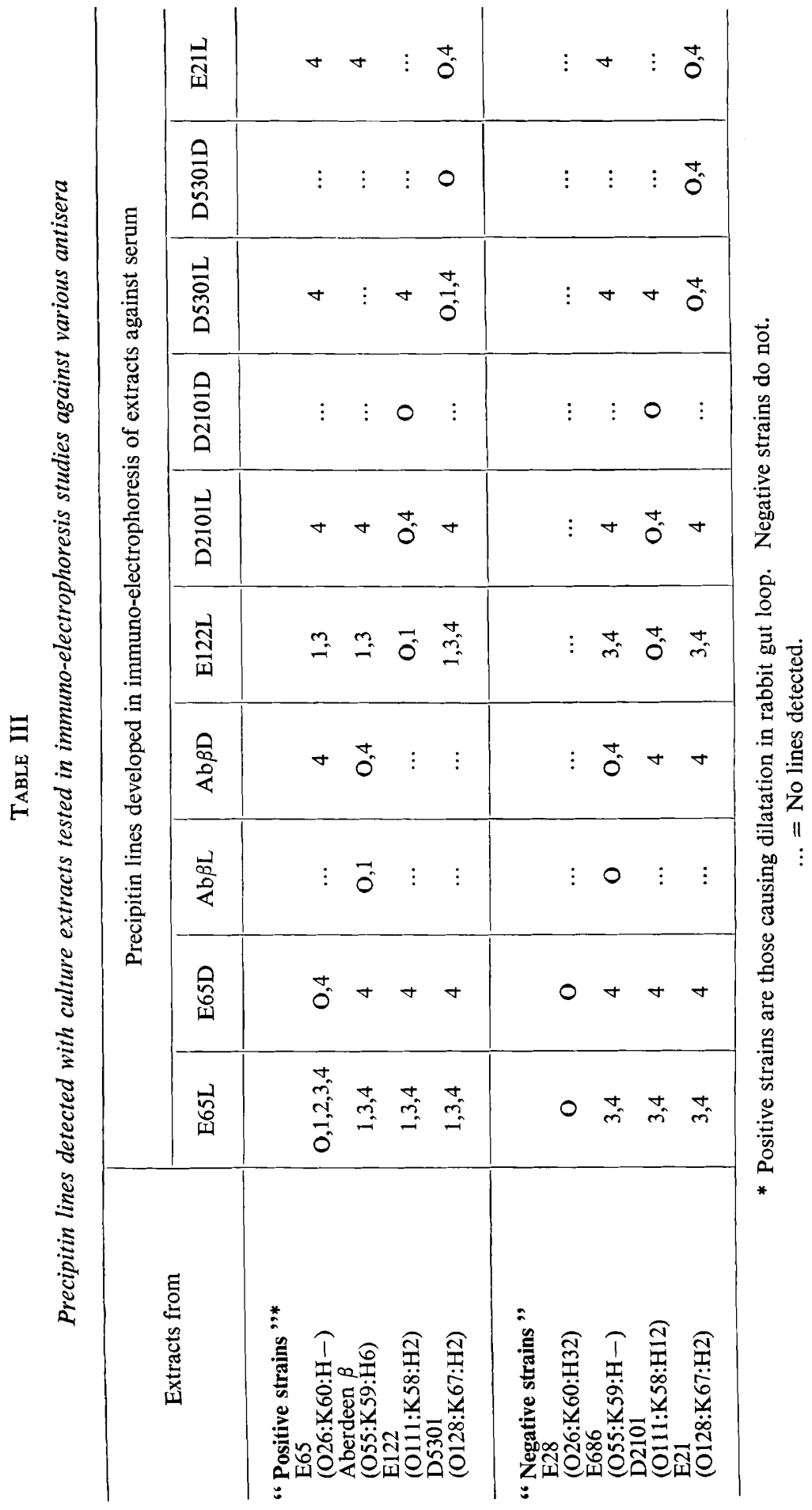


of diffusible antigens was carried out in three stages. All antigen preparations were tested for line-1 production by immuno-electrophoresis with the two antisera that gave the best results with gut loop antigens already described. The two antisera were E65L prepared with $E$. coli $\mathrm{O} 26: \mathrm{K} 60: \mathrm{H}$ - and E122L prepared with O111:K58:H2. Those extracts that produced line 1 with one or both sera were then tested by simple gel-diffusion against a further six antisera. Three sera were prepared against alcohol-killed inocula of strains E65, Aberdeen $\beta$ and D5301 and three against living inocula of Aberdeen $\beta$, D2101 and D5301; the antigenic structures of the strains used are shown in table I. As shown in table III, antisera prepared against Aberdeen $\beta \mathbf{L}$ and D5301L contained line- 1 antibodies, but the known antigenic structures of these strains are different from those of strains E65 and E122. The four D sera do not contain line- 1 antibodies, but each contains the same $\mathrm{O}$ and $\mathrm{K}$ antibodies as one of the four L sera that contains line-1 antibodies. By this test it was expected that serological relationships would be revealed other than those indicated by the known and accepted $\mathrm{O}, \mathrm{K}$ and $\mathrm{H}$ antigens.

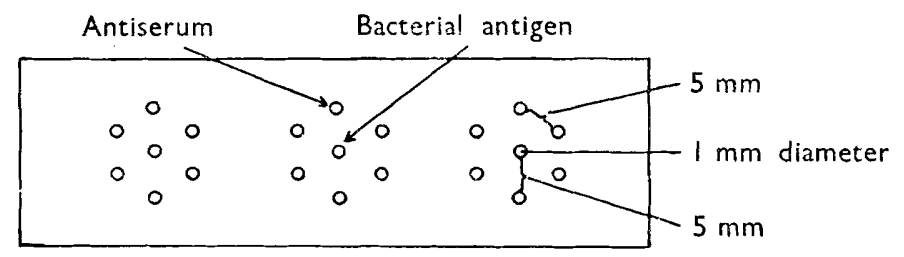

FIG. 3.-Gel-diffusion test plate.

The simple gel-diffusion was performed on agar-covered glass slides prepared in the same way as for immuno-electrophoresis. Holes were punched with a template (see fig. 3). The antigen was placed in the central hole and antisera in the surrounding holes. The slides were incubated at room temperature in a humid atmosphere for $1 \mathrm{wk}$ then washed in buffer, dried and stained with amido black.

Any antigen preparation that produced one or more precipitin lines was then tested by immuno-electrophoresis against those antisera giving positive reactions, in order to assess the significance of the lines after further differentiation.

It was found that not only were precipitin lines obtained when the known antigens of the strains under test corresponded to the known serum antibodies, but that lines occurred even when there was no known relationship. Lines that developed in the simple gel-diffusion system as a result of interactions between antigens and antisera with no known relationships included the line-1 complex, but true differentiation could be obtained only by immunoelectrophoresis.

Survey of 375 strains of E. coli from various human sources. A total of 375 strains isolated from human sources and of known serotype were tested. Three hundred and sixteen were isolated from the faeces of babies with diarrhoea, 39 from the faeces of healthy babies, 17 from infected urine, two from vaginal swabs and one from cerebrospinal fluid (CSF). Line 1 was never formed by 
strains from healthy babies, or by strains derived from urinary infections, vaginal swabs or the CSF sample. Line 1 was formed by 99 of the 316 strains isolated from babies with diarrhoea (table IV).

The antigenic structures of all strains investigated were identified as far as possible and classified according to the international scheme. Table V shows the antigenic structures of " line-1-positive" strains and the number of strains that were identical in $\mathrm{O}, \mathrm{K}$ and $\mathrm{H}$ antigens but "line-1-negative" which were isolated from babies with diarrhoea and healthy babies.

Survey of 25 strains from animal sources. A further 25 strains were tested that had been derived from animal sources including mouse (1), pigs (5), monkeys (2), puma (1), rabbit (1), chickens (7), pigeons (3), turkey (1) and calves (4). The histories of many of the animals were unknown, though some died

TABLE IV

Results of tests for line-1 antigen in 355 routine faecal strains of Escherichia coli isolated from babies

\begin{tabular}{c|c|c}
\hline $\begin{array}{c}\text { Number of strains } \\
\text { tested }\end{array}$ & $\begin{array}{c}\text { Condition } \\
\text { of baby }\end{array}$ & $\begin{array}{c}\text { Number of strains } \\
\text { showing presence }(+) \text { or absence }(-) \\
\text { of line-1 antigen }\end{array}$ \\
\hline 39 & Healthy & $0+, 39-$ \\
\hline 316 & Diarrhoeal disease & $99+, 217-$ \\
\hline
\end{tabular}

of septicaemic illnesses. The monkeys were known to be healthy, one calf was scouring and the strain produced a line 1 ; the history of the other three calves is not known and line 1 was not produced. One sow was known to scour, but the strains failed to produce line 1; three other strains from pigs whose histories were unknown also failed to produce a line 1. The strains from the other animals all failed to produce a line 1.

\section{Discussion}

Escherichia coli is normally found in specimens of faeces from healthy man and from patients with diarrhoea. The majority of strains can be typed according to the international antigenic scheme and, though certain serotypes are common in patients with diarrhoea, they may be isolated from " normal" specimens. The belief that certain serotypes cause diarrhoea rests on epidemiological findings, the effect of human feeding experiments and the finding that strains causing human diarrhoea also cause dilatation of the ligated rabbit gut loop. Because the gut loop test is clumsy, time-consuming and not always reliable, we decided to try other methods of testing for enterotoxicity.

Certain of our laboratory strains had been used repeatedly in experimental work and their effect on the ligated gut loop was well known. Although those strains that produce dilatation of the gut loop tended to cause a less marked reaction after storage, we knew that they still retained their activity. On 
TABLE V

Relation of serotype, line-1 antigen and association with human diarrhoeal disease in 236 strains of Escherchia coli isolated from the faeces of babies

\begin{tabular}{|c|c|c|}
\hline \multirow{2}{*}{$\begin{array}{l}\text { Serotype } \\
\text { of } E \text {. coli }\end{array}$} & \multicolumn{2}{|c|}{$\begin{array}{l}\text { Number of strains with line-1 } \\
\text { antigen present }(+) \text { or absent }(-) \text { and } \\
\text { associated with }\end{array}$} \\
\hline & diarrhoea & health \\
\hline 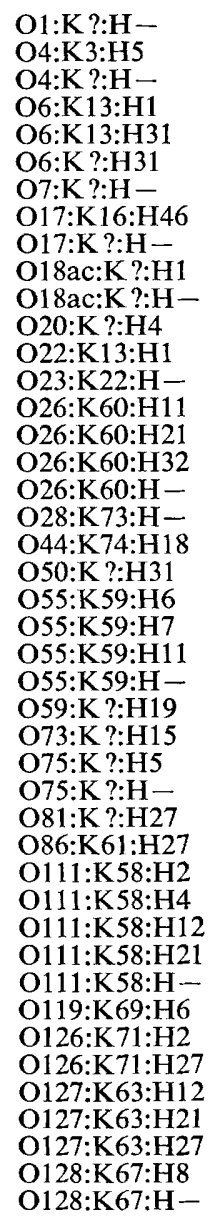 & $\begin{array}{l}2+, 4- \\
2+, 2- \\
1+, \ldots \\
2+, 1- \\
1+, 4- \\
1+, \ldots \\
1+, \ldots \\
1+, \ldots \\
1+, \ldots \\
1+, \ldots \\
1+, \ldots \\
1+, \ldots \\
1+, 1- \\
1+, \ldots \\
14+, 1- \\
1+, \ldots \\
2+, \ldots \\
5+, 7- \\
1+, 1- \\
1+, \ldots \\
1+, \ldots \\
2+, 1- \\
9+, 20- \\
1+, \ldots \\
1+, 2- \\
2+, \ldots \\
1+, \ldots \\
2+, 9- \\
1+, 8- \\
1+, \ldots \\
1+, 3- \\
1+, \ldots \\
1+, \ldots \\
3+, 7- \\
1+, \ldots \\
6+, 11- \\
1+, 1- \\
14+, 15- \\
1+, 3- \\
1+, \ldots \\
1+, 3- \\
1+, 1- \\
1+, 2- \\
4+, 1-\end{array}$ & 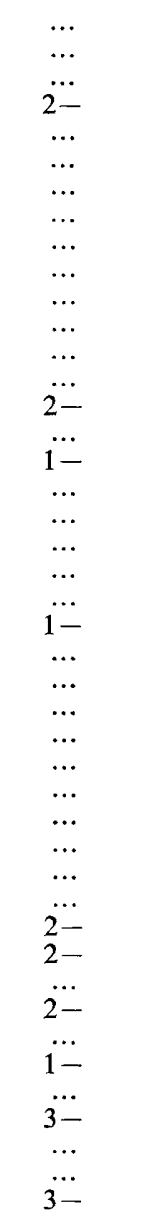 \\
\hline Total & $99+, 118-$ & $0+, 19-$ \\
\hline
\end{tabular}

the other hand, as the amount of exudate produced tends to be greater with passage when rabbit gut exudate is inoculated into further rabbits, we suspected that larger amounts of enterotoxin are produced in this model. This could be 
the result of enhancement of certain properties of the organism alone or the exudate might contain toxins resulting from the action of the organisms on the tissues. It was with these thoughts in mind that the decision was made to use extracts of gut exudates in the first experiments.

The same thoughts were important in relation to the method of preparing antisera, for if an enterotoxin or additional amount of enterotoxin is formed by the interaction of organisms and tissues it would be wise to use a living vaccine. Previous work had shown that even when enterotoxin was present in killed cultures it was extremely labile, so that a killed vaccine might fail to stimulate the production of anti-enterotoxic antibodies. It is known that alcohol-killed vaccines produce antibodies to the known $\mathrm{O}$ and $\mathrm{K}$ somatic antigens; in order to decide whether these antigens were related to enterotoxin production, four antisera were made from alcoholised suspensions of the same strains as were used in the living vaccines. In addition two other strains with the same $O$ and $K$ structure as two of the previous four strains were used again because it was believed that these antisera would assist in the interpretation of precipitin lines caused by somatic or other antigens. The reactions of all six strains in the ligated gut loop test were known, a positive reaction being accepted as a sign of enterotoxin production.

When the crude antigen was subjected to an electric current, the component somatic antigens moved towards the cathode, and other antigens moved towards the anode and were detected by precipitation reactions with antisera. The somatic precipitin line appeared only when the antigen was tested against sera prepared against a living or dead preparation of organisms of the same OK serotype. On the anode side a number of lines appeared, but a precipitation band designated line 1 was produced only by exudates obtained from dilated gut; the development of this line was unrelated to any obvious homology between the known antigenic structure of the test strain and that of the strain used in the preparation of the antiserum.

No lines appeared when material from uninoculated rabbit gut was tested against the various antisera.

Similar results were obtained when extracts of cultures were used as antigens, line 1 being produced only by strains that caused dilatation of the rabbit gut when tested against $\mathrm{L}$ sera made from certain gut-dilating strains. The development of other lines ( 3 and 4 ) was unrelated to the known antigenic structure of the strains and bore no relation to their enterotoxic properties. For example, extracts of four gut-dilating strains E65, Aberdeen $\beta$, E122 and D5301 produced line 1 when tested against antisera E65L and E122L, but failed to produce this line when tested against antisera E65D and E122D. Aberdeen $\beta$ and D5301 are known gut-dilating strains, yet $L$ antisera from these produce line 1 when tested against the homologous extract only. It is possible that these strains produced less line-1 antibody than strains E65 and E122. It is interesting that line-1 antibody was not detectable in L or D sera prepared from strain D2101. This was shown by testing extracts of strains E65, Aberdeen $\beta$, E122 and D5301. Strains D2101, E28, E686 and E21 were isolated from healthy babies and failed to cause dilatation of gut loops. 
We now believed that the production of line 1 was related to the enterotoxic potential of a strain and decided to test strains of $E$. coli isolated from babies with diarrhoea. These strains were isolated in many different laboratories and only one strain per baby was investigated. It is possible that the causal organisms may not have been sent or that the symptoms were due to causes other than E. coli. The antigenic structure of each strain was identified and then extracts were tested by immuno-electrophoresis. Table IV shows that only 99 of 316 strains from babies with diarrhoea gave line 1; on the other hand, all 39 strains from healthy babies failed to produce line 1 .

Table $\mathrm{V}$ shows that those strains producing line 1 represented 24 different O groups, many of which are not known to be associated with human diarrhoeal disease. Many of these serotypes failed to produce line 1 even though they were isolated from babies with diarrhoea, but these same serotypes from healthy babies never gave a line-1 precipitation band.

Results of investigations of outbreaks of infantile diarrhoea and evidence from feeding experiments show that certain serotypes such as 0111 and 055 cause diarrhoea. On the other hand, these same types have been isolated from healthy babies and this suggests that a serotype may sometimes be enterotoxic and sometimes may not have this property. We believe that the use of immunoelectrophoresis with antisera produced against living enterotoxic strains in the manner described may allow the detection of enterotoxic $E$. coli. Obviously more work is needed, for line 1 may indicate only one type of enterotoxic agent and there may be others. Further studies may make it possible to produce a more potent antigen and anti-enterotoxic serum. Our attempt to do so in the present study with an azide extract as the immunising antigen failed.

It is interesting that one strain isolated from calf scours, E. coli O26:K60: H11, produced line 1. This particular strain was not tested in rabbit gut loop, but other calf strains have caused dilatation in this model. It is possible that the enterotoxin produced by some calf strains may be related to that produced by human strains.

\section{SUMMARY}

An immuno-electrophoretic procedure is described for the detection of soluble bacterial antigens in culture extracts, and in material from ligated rabbit gut loops. All material examined in this study was derived from fully identified strains of Escherichia coli and rabbit gut loop exudates. A precipitin line, referred to as line 1 , was produced when antisera ( $L$ sera) prepared with living vaccines were tested in the system against $E$. coli-induced gut exudates or extracts of cultures that evoked gut exudates. Rabbit antisera prepared in response to dead vaccines (D sera) of strains known to be enterotoxic to man did not produce line 1 , nor was this precipitin band produced when $L$ sera were tested against (i) the media used, (ii) normal rabbit gut washings, or (iii) extracts of $E$. coli that failed to dilate rabbit gut.

This study was extended to a survey of strains of $E$. coli isolated from healthy babies, from babies with diarrhoea, from urinary tract infections and other sources in man, and from various species of animals. 
Line 1 was never produced by extracts of strains of $E$. coli isolated from the following human material: 39 faecal strains from healthy babies, 17 strains from infected urines, 2 strains from vaginal swabs and 1 from a sample of cerebrospinal fluid; nor was line 1 produced by 24 strains of animal origin. Ninety-nine of the 316 strains isolated from the faeces of babies with diarrhoea and 1 strain isolated from the faeces of a scouring calf produced line 1 .

We wish to thank Miss M. Smith and Mr D. P. Woodroof for invaluable technical assistance and we thank Messrs Oxoid for providing dried whey.

\section{REFERENCES}

Bettelheim, K. A. . . . . . . . . 1969. Ph.D. Thesis, Univ. London.

De, S. N., Bhattacharya, K., and 1956. J. Path. Bact., 71, 201.

SARKAR, J. K.

EWING, W. H. . . . . . . . . 1956. Publ. Hlth Lab., 14, 138.

Ferguson, W. W., and June, R. C. . . 1952. Amer. J. Hyg., 55, 155.

KAUfFMANN, F. . . . . . . . 1969. The bacteriology of Enterobacteriaceae, 2nd ed., Copenhagen, pp. 35-40.

Neter, E., and Shumway, Clare N. . 1950. Proc. Soc. Exp. Biol. Med., 75, 504.

Smith, H. W., ANd Halls, Sheila . . 1967a. J. Path. Bact., 93, 499.

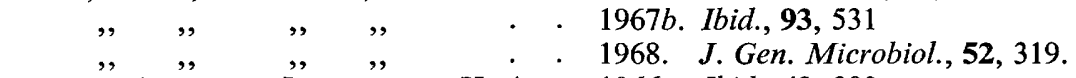

TAYLOR, JoAN, AND BETTELHEIM, K. A. . 1966. Ibid., 42, 309.

Taylor, Joan, Maltby, M. Patricia, 1958. J. Path. Bact., 76, 491. AND PAYNe, J. M.

Taylor, Joan, Wilkins, M. Patricia, 1961. Br. J. Exp. Path., 42, 43. AND PAYNe, J. M. 